Article

\title{
Bioconversion of Biomass-Derived Phenols Catalyzed by Myceliophthora thermophila Laccase
}

\author{
Anastasia Zerva ${ }^{1}$, Nikolaos Manos ${ }^{1}$, Stamatina Vouyiouka ${ }^{2}$, Paul Christakopoulos ${ }^{3}$ \\ and Evangelos Topakas $1,3, *$ \\ 1 Biotechnology Laboratory, School of Chemical Engineering, National Technical University of Athens, \\ 5 Iroon Polytechniou Str., Zografou Campus, Athens 15780, Greece; natassaz@gmail.com (A.Z.); \\ nickgmanos@gmail.com (N.M.) \\ 2 Laboratory of Polymer Technology, School of Chemical Engineering, National Technical University of Athens, \\ 5 Iroon Polytechniou Str., Zografou Campus, Athens 15780, Greece; mvuyiuka@central.ntua.gr \\ 3 Biochemical and Chemical Process Engineering, Division of Sustainable Process Engineering, \\ Department of Civil, Environmental and Natural Resources Engineering, Luleå University of Technology, \\ Luleå SE-97187, Sweden; paul.christakopoulos@ltu.se \\ * Correspondence: vtopakas@chemeng.ntua.gr; Tel.: +30-210-772-3264
}

Academic Editor: Derek J. McPhee

Received: 26 January 2016; Accepted: 22 April 2016; Published: 27 April 2016

\begin{abstract}
Biomass-derived phenols have recently arisen as an attractive alternative for building blocks to be used in synthetic applications, due to their widespread availability as an abundant renewable resource. In the present paper, commercial laccase from the thermophilic fungus Myceliophthora thermophila was used to bioconvert phenol monomers, namely catechol, pyrogallol and gallic acid in water. The resulting products from catechol and gallic acid were polymers that were partially characterized in respect to their optical and thermal properties, and their average molecular weight was estimated via solution viscosity measurements and GPC. FT-IR and ${ }^{1} \mathrm{H}-\mathrm{NMR}$ data suggest that phenol monomers are connected with ether or $\mathrm{C}-\mathrm{C}$ bonds depending on the starting monomer, while the achieved molecular weight of polycatechol is found higher than the corresponding poly(gallic acid). On the other hand, under the same condition, pyrogallol was dimerized in a pure red crystalline compound and its structure was confirmed by ${ }^{1} \mathrm{H}-\mathrm{NMR}$ as purpurogallin. The herein studied green synthesis of enzymatically synthesized phenol polymers or biological active compounds could be exploited as an alternative synthetic route targeting a variety of applications.
\end{abstract}

Keywords: laccase; enzymatic oligomerization; catechol; pyrogallol; gallic acid

\section{Introduction}

Recently, phenol polymers have attracted increasing attention as novel materials with various useful properties and applications. Research efforts are mainly focusing on the manufacture of novel polyphenols as an alternative to phenol-formaldehyde resins, widely used as adhesives, electric coatings and composites [1]. Despite their numerous applications, the present phenol-formaldehyde resin manufacturing processes pose many issues. Chemical synthesis of such products requires the use of inorganic catalysts, often of high cost and toxicity, and is usually carried out under extreme conditions of pressure, temperature and $\mathrm{pH}$ [2]. Thus an alternative procedure might be preferable, with low cost, environmentally friendly catalysts, carried out in milder conditions. Enzymes derived from various sources, from plants to microorganisms, can fulfil this need. Oxidoreductive enzymes, such as laccases [3], peroxidases [4,5], tyrosinases [6] or bilirubin oxidases [7] oxidize a variety of phenols, producing free radicals that are further subject to spontaneous polymerization. 
Laccases in particular are extensively studied in regard to phenols polymerization [2,3,8-10]. Laccase-synthesized phenol polymers have been tested in numerous applications, such as hair [11] or textile dyeing $[3,10,12,13]$. Some polyphenols seem to possess antioxidant properties that may be useful in the food, cosmetics or pharmaceutical industry [14]. Others have been tested as possible biosensors, due to the fact that some polyphenols, such as polycatechol or polyhydroquinone exhibit a certain extent of electrical conductivity [15-18]. Most polymerization efforts so far have been realized with commercial laccase from Trametes versicolor [11,19]. However, other commercial laccases, possibly with superior properties are also available, such as laccase from Myceliophthora thermophila expressed in Aspergillus oryzae $[3,10,14]$. The main advantage of Ascomycete laccases in biocatalysis is their higher thermostability and stability in a greater $\mathrm{pH}$ range, in contrast to Basidiomycete laccases, and thus they might be useful in a greater variety of applications. The difference in the use of a different biocatalyst may lie either in the optimization of the process parameters (enzyme stability, operation in preferable conditions) or even in the properties of the final product (bonds formed, polymerization degree and molecular weight, or overall material properties, such as thermoresistance or electrical conductivity). In this view, it might be useful to test the performance of various enzymes from different sources and with distinct properties in order to optimize the polymerization process and explore the properties's variability of the resulting products. For example, oligomers of naturally occurring phenols might possess properties of great significance, applicable in medical or other industries, as is the case of purpurogallin, a pyrogallol dimer with beneficial human health effects [20-22].

In the present work, the polymerization or dimerization potential of a M. thermophila commercial laccase was explored, in an effort to obtain new biomaterials and antioxidants for various applications following a green and sustainable process. The effect of $\mathrm{pH}$ and temperature conditions for the synthesis of polycatechol and purpurogallin were investigated, aiming in optimizing the reaction conditions. The optimal conditions were retained for the bioconversion of gallic acid aiming in the biocatalytic production of novel polymers and antioxidants. The polymers produced were partially characterized in respect to their spectral and thermal properties. The dimerization of pyrogallol by the commercial laccase synthesized purpurogallin is a direct and mild process resulting in a pure compound without the need of any purification steps. The results of the study illustrate the superiority of enzyme biocatalysts in the production of materials and compounds from biomass derived phenols on behalf of the biorefinery concept.

\section{Results and Discussion}

\subsection{Effect of $\mathrm{pH}$ and Temperature in Phenol Bioconversion}

In order to find the functional conditions where the enzyme catalyzes the oxidative bioconversion of various phenols, we studied the effect of $\mathrm{pH}$ and temperature for the polymerization of catechol and pyrogallol dimerization. The best conditions for $M$. thermophila laccase reactions were found similar in $\mathrm{pH}$ ( $\mathrm{pH} 6$ for catechol polymerization and $\mathrm{pH} 5$ for pyrogallol dimerization), while in both reactions $30^{\circ} \mathrm{C}$ was found as the optimal temperature, despite the thermophilic nature of the biocatalyst (Figure 1). This result might be due to the higher solubility of dioxygen, a necessary co-substrate for laccase catalysis, in lower temperatures. Similar conditions $\left(\mathrm{pH} 6,30^{\circ} \mathrm{C}\right)$ were applied for the bioconversion of gallic acid, as no study of the optimal conditions was carried out due to the low conversion yield obtained.

The dry powder resulting from the polymerization of catechol was insoluble in water, phosphate buffer $\mathrm{pH} 6$ and acetic acid, but also in a number of organic solvents, such as ethanol, methanol, acetonitrile, acetone, $n$-hexane and methyl ethyl ketone. From the tested solvents, polycatechol was found to be soluble only in DMSO, tetrahydrofuran and dimethylformamide, and to a lesser extent, at $1 \mathrm{~N} \mathrm{NaOH}$. The subsequent bioconversion reactions were performed at $\mathrm{pH} 6$ and $30^{\circ} \mathrm{C}$. 

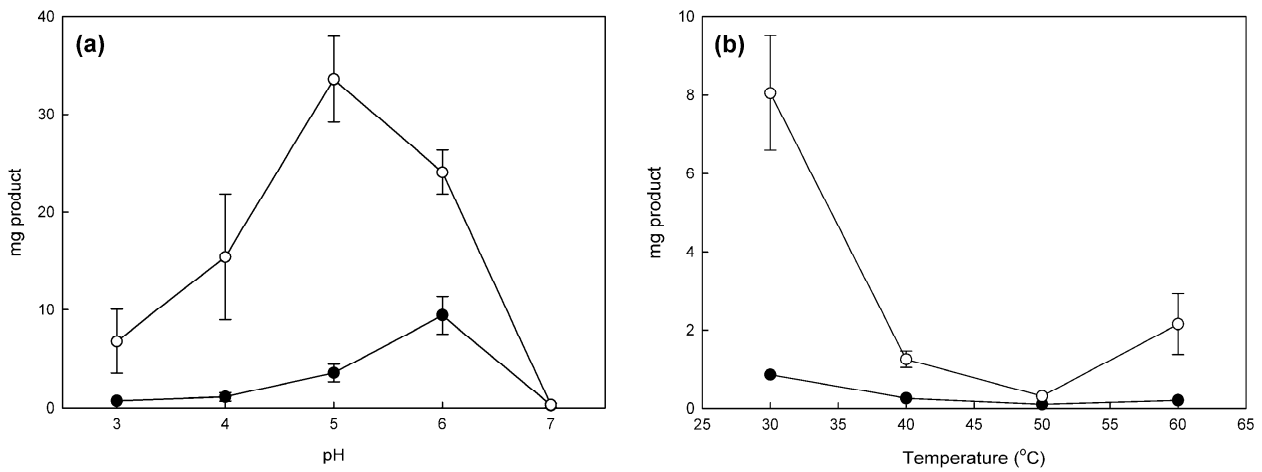

Figure 1. Effect of (a) $\mathrm{pH}$ and (b) temperature in polymerization reactions of catechol (black circles) and pyrogallol (white circles) from $M$. thermophila laccase under standard conditions performed in $25 \mathrm{~mL}$ reactions. Error bars represent the standard deviation from duplicate reactions.

\subsection{Preparative Synthesis and Product Characterization}

The $100 \mathrm{~mL}$ reaction mixtures yielded $105 \mathrm{mg}, 142 \mathrm{mg}$, and $18.6 \mathrm{mg}$ of dry powder for polycatechol, purpurogallin and poly(gallic acid) respectively, after $24 \mathrm{~h}$ at $30^{\circ} \mathrm{C}$. The corresponding yields for the two polymers were $26.3 \%$ and $4.7 \%$ for polycatechol and poly(gallic acid), respectively, while for the bioconversion of pyrogallol it was $35.5 \%$ with regard to the precipitate formed. Contrary to previous enzymatic phenol polymerization attempts using high redox potential Basidiomycete laccases, in the present study the use of organic solvents was not necessary, either during the reaction [2], or for the isolation of the final products [23].
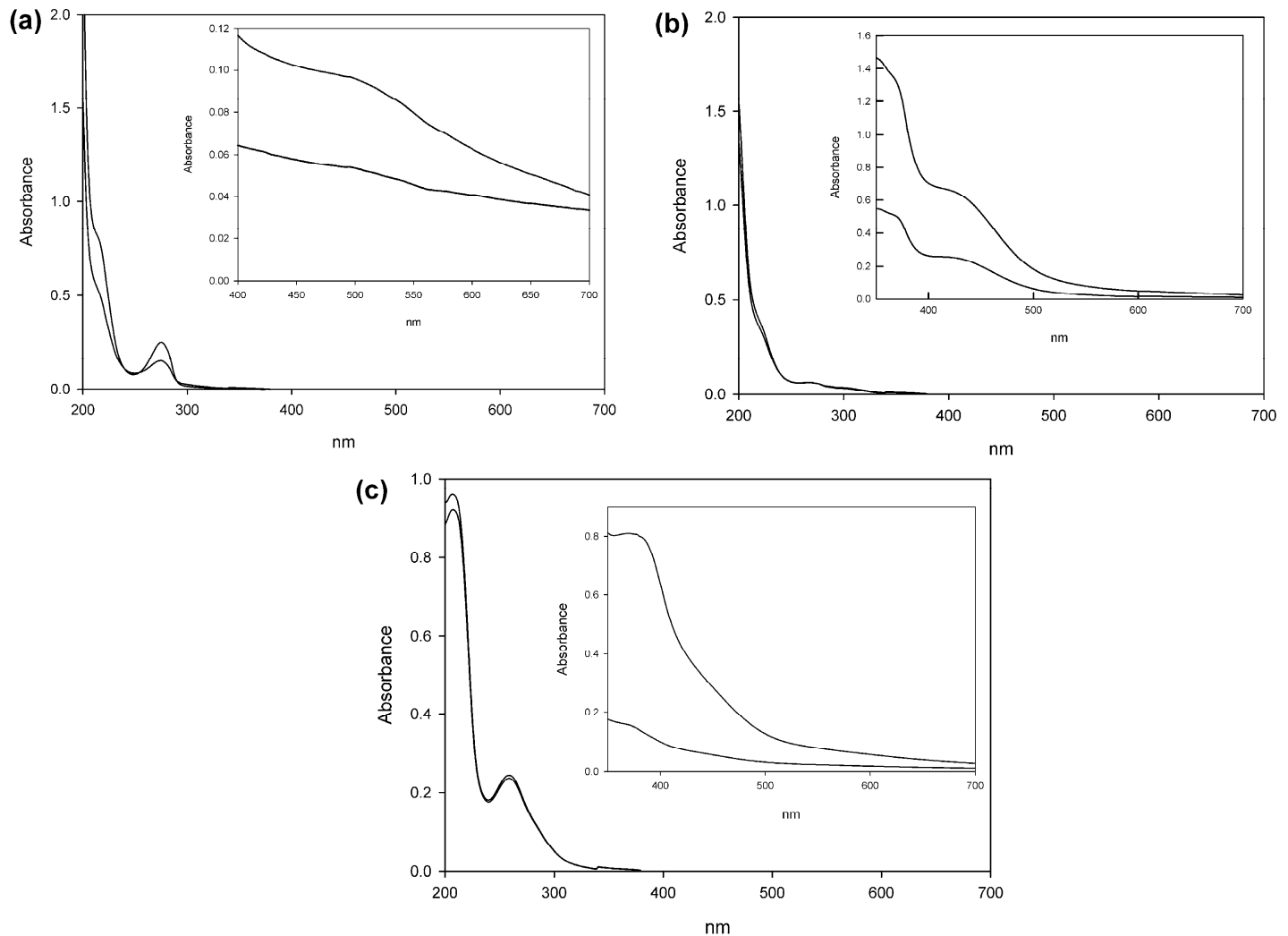

Figure 2. UV-Vis spectra of polymerization or dimerization products with catechol (a); pyrogallol (b); and gallic acid (c) as starting monomers. Grey lines represent the control reactions where laccase was substituted with heat-inactivated enzyme, while black lines represent the reaction mixtures after $24 \mathrm{~h}$. The UV-Vis spectra presented correspond to 100-fold diluted samples, while in the inlets the spectra were recorded without any dilution. 
All reaction mixtures changed colour from colourless to dark brown during oxidation of catechol and pyrogallol, and to black during oxidation of gallic acid, as is often reported for the enzymatic oxidation of phenolic compounds [3]. UV-Vis spectra were measured for all the reactions against their respective controls (Figure 2). Polycatechol absorbance is consistently higher than the control in the visible spectrum, presenting a wide peak around $463 \mathrm{~nm}$. Polymerized gallic acid presents a significant increase in absorbance at $385 \mathrm{~nm}$ compared to the control. Purpurogallin presents peaks at the same wavelengths as the control in the ultraviolet area of the spectrum, but also shows two distinctive peaks in 370 and $430 \mathrm{~nm}$.

The weight of the products measured corresponds only to the insoluble polymers or dimers that precipitate out of the reaction solution. This could partly explain the low yields obtained, especially in the case of gallic acid polymerization, seeing that the soluble poly- or oligomers are not measured in the precipitate, but rather are responsible for the colour of the reaction mixture, as indicated by the UV/Vis spectra. Possible differences in colour could be used as a means to quantify these soluble polyor oligomers in the reaction supernatant. Colour darkening during the course of the reaction could also be attributed to the quinones formed by the action of the enzyme [24]. In the above described experiments it is apparent that the use of organic solvents was not required in the reaction mixture, contrary to previous studies $[25,26]$.

\subsection{Spectroscopic Analysis of Products}

The FT-IR spectra of all three products were considerably smoother, probably due to the limited mobility of the side substituents especially in case of polymers, leading to a more rigid final product (Figure 3). In all three cases the sharp multiple monomer bands in the range 3000-3600 nm, usually attributed to the phenolic - $\mathrm{OH}$ moieties, were replaced by a broader band around $3400 \mathrm{~nm}$ in the polymer spectra. This is often observed in the case of phenol polymers and is attributed to the higher rigidity of the polymer, due to intramolecular hydrogen bonding, and to the limited mobility of the remaining free hydroxyl groups [25]. Polycatechol presents characteristic peaks in either ends of the $1000-1300 \mathrm{~cm}^{-1}$ range, consistent with the existence of $\mathrm{C}-\mathrm{O}-\mathrm{C}$ bond, as reported previously $[3,25,26]$. More specifically, for polycatechol, the peaks at 1250 and $1070 \mathrm{~nm}$ clearly indicate the presence of phenyl ether bonds, as previously described (Figure 3a; [26]).

The band at $1606 \mathrm{~nm}$ could be attributed to the $\mathrm{C}=\mathrm{O}$ bond of the quinone resulting from laccase oxidation. Characteristic peaks in the polymerized gallic acid spectrum correspond to wavelengths of 1586, 1500, $1378 \mathrm{~nm}$, a shoulder at $1320 \mathrm{~nm}$, and $1010 \mathrm{~nm}$ (Figure 3b). As previously described [26], peaks that could be attributed to the existence of $\mathrm{C}-\mathrm{O}-\mathrm{C}$ bonds were not observed, leading to the conclusion that the gallic acid monomers are joined with $\mathrm{C}-\mathrm{C}$ bonds. The FT-IR spectrum of the pyrogallol bioconversion product is shown in Figure 3c. The $\mathrm{C}=\mathrm{O}$ bond of the quinone formed from laccase oxidation of pyrogallol is possibly represented by the peak at $1603 \mathrm{~nm}$. The bands observed correspond to those previously reported for purpurogallin, a pyrogallol dimer [20], namely 3381, 1374, 1238 and $1012 \mathrm{~nm}$. The ${ }^{1} \mathrm{H}-\mathrm{NMR}$ spectra for the laccase catalysed synthesized polymers confirmed the above mentioned characterization, while in the case of pyrogallol dimerization to purpurogallin the purity and structure of the final product was identified. The proton NMR spectrum of the polycatechol product presents multiple peaks in the aromatic area between 6.2 and 7.5 ppm (Figure S1). Combining the ${ }^{1} \mathrm{H}-\mathrm{NMR}$, FT-IR spectra together with literature data, we hypothesize a complex structure that could be a combination of proposed structures found in previous studies, as shown in Figure 4a [3,18]. 
(a)

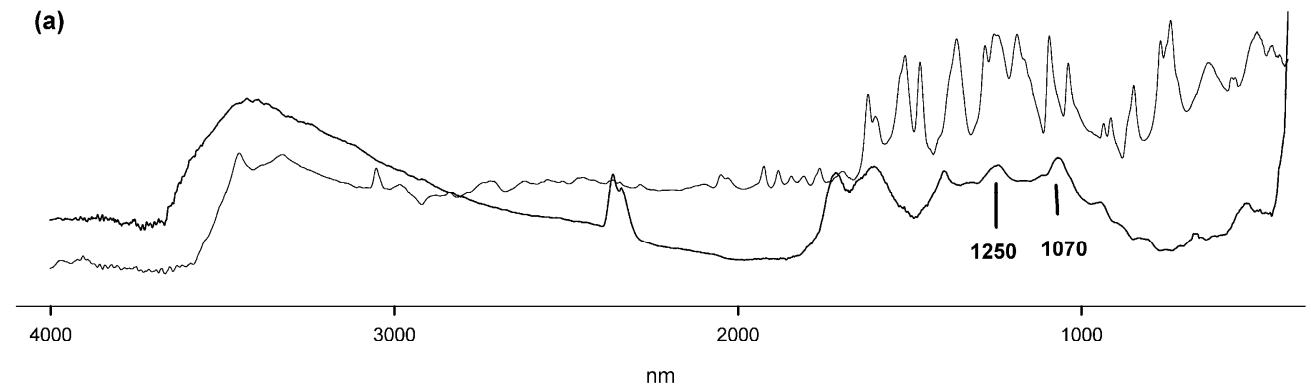

(b)
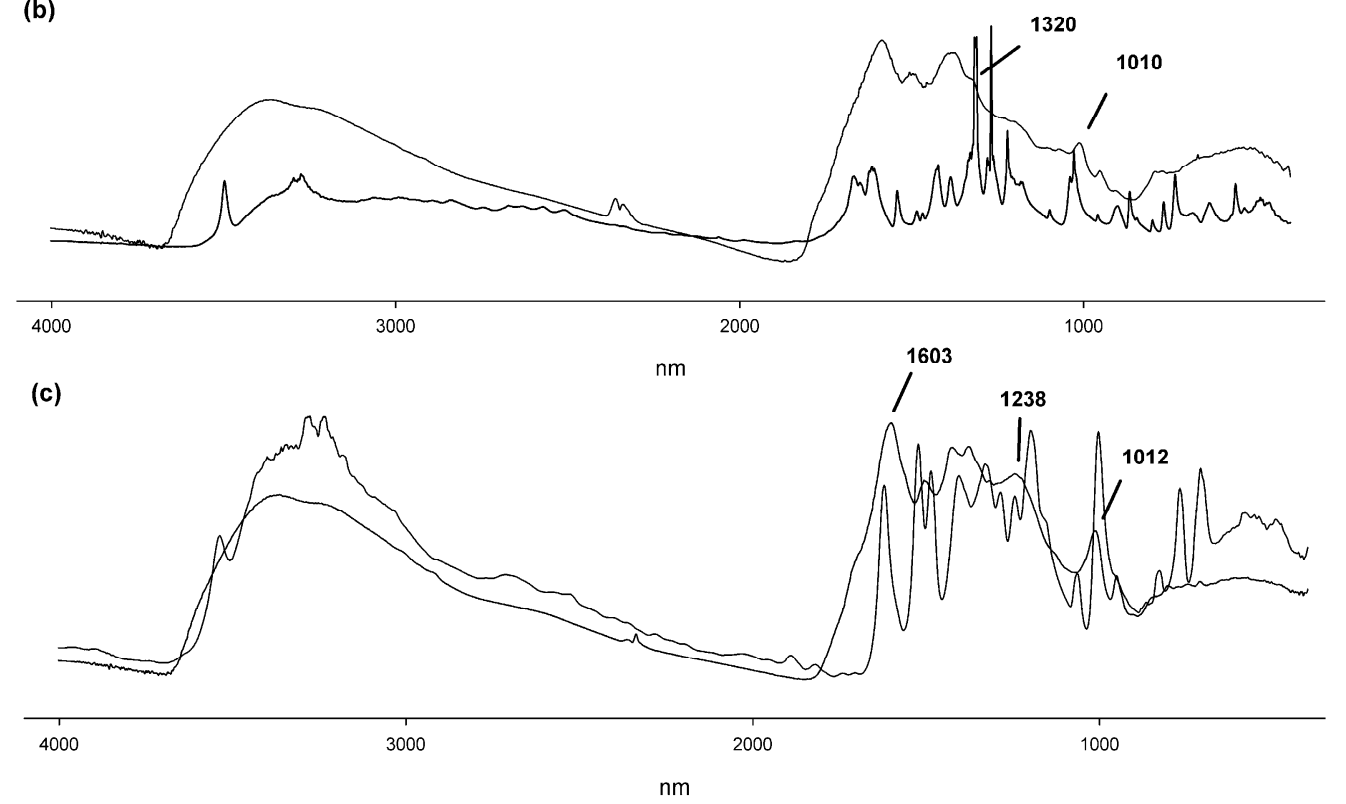

Figure 3. FT-IR spectra of the synthesized products and the respective monomers, (a) catechol; (b) gallic acid; (c) pyrogallol. Grey lines represent the monomer spectra, black lines represent the polymers. Characteristic peaks and shoulders, as referred to in the text, are indicated.

(a)

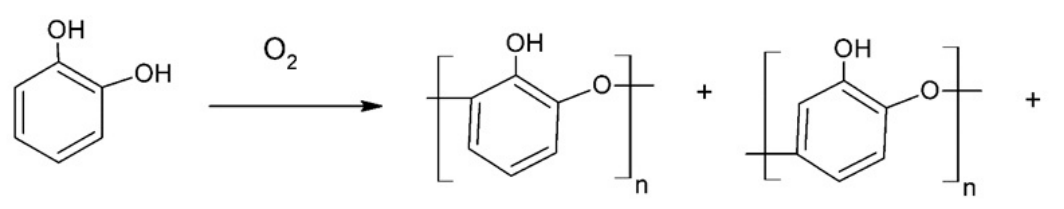

(b)<smiles>CC(C)(C)c1c(O)c(O)c(C(C)(C)C)c(C(=O)O)c1O</smiles>

(c)<smiles>Oc1cccc(O)c1O</smiles><smiles>O=c1c(O)cccc2cc(O)c(O)c(O)c12</smiles>

Figure 4. Enzymatic polymerization of (a) catechol; (b) gallic acid and dimerization of (c) pyrogallol by the commercial laccase from $M$. thermophila. 
In case of poly(gallic acid), the commercial laccase from $M$. thermophila was capable of catalyzing only the polymerization through $\mathrm{C}-\mathrm{C}$ coupling of the aromatic chain, as previously reported [26]. This is clearly observed from the ${ }^{1} \mathrm{H}-\mathrm{NMR}$ spectrum where no signals were detected in the aromatic proton area, compared to the monomer of gallic acid where a singlet was observed at $6.81 \mathrm{ppm}$ corresponding to two aromatic protons (data not shown). The structure elucidated in Figure $5 \mathrm{~b}$ is identical to the poly(gallic acid) produced by oxidative polymerization of T. versicolor laccase, resulting in a semiconducting material [26]. On the other hand, pyrogallol was dimerized by M. thermophila laccase resulting in purpurogallin shown in Figure 5c. The dimerization product precipitated and the starting material was identified in the supernatant, therefore washing the crystal product with water yielded a pure biologically active compound. The pure compound was dissolved in DMSO- $d_{6}$ and analyzed by ${ }^{1} \mathrm{H}-\mathrm{NMR}$. The corresponding spectrum differs considerably to the monomer of pyrogallol where only two peaks were detected at $6.32 \mathrm{ppm}(\mathrm{t}, J=8.0 \mathrm{~Hz}, 1 \mathrm{H})$ and $6.15(\mathrm{~d}, J=8.0 \mathrm{~Hz}, 2 \mathrm{H}) \mathrm{due}$ to the symmetric structure of the aromatic compound (spectrum not shown). As illustrated in the ${ }^{1} \mathrm{H}-\mathrm{NMR}$ spectrum (Figure S2), the aromatic protons were replaced by alkenyls as revealed by their corresponding coupling constants at $7.25 \mathrm{ppm}(\mathrm{d}, J=11.4 \mathrm{~Hz}, 1 \mathrm{H}), 6.98 \mathrm{ppm}(\mathrm{d}, J=9.4 \mathrm{~Hz}, 1 \mathrm{H})$ and $6.64(\mathrm{dd}, J=11.3,9.5 \mathrm{~Hz}, 1 \mathrm{H})$. The single aromatic proton found in the structure of purpurogallin was detected at $6.80 \mathrm{ppm}(\mathrm{s}, 1 \mathrm{H})$ as a broad singlet (Figure S2). The peaks observed in the spectrum of the pyrogallol polymerization product are consistent with those reported previously for pyrogallol dimer, purpurogallin [20]. Based on these results, in combination with data from related literature, we propose structures for these polyphenols or dimers, as presented in Figure 4.
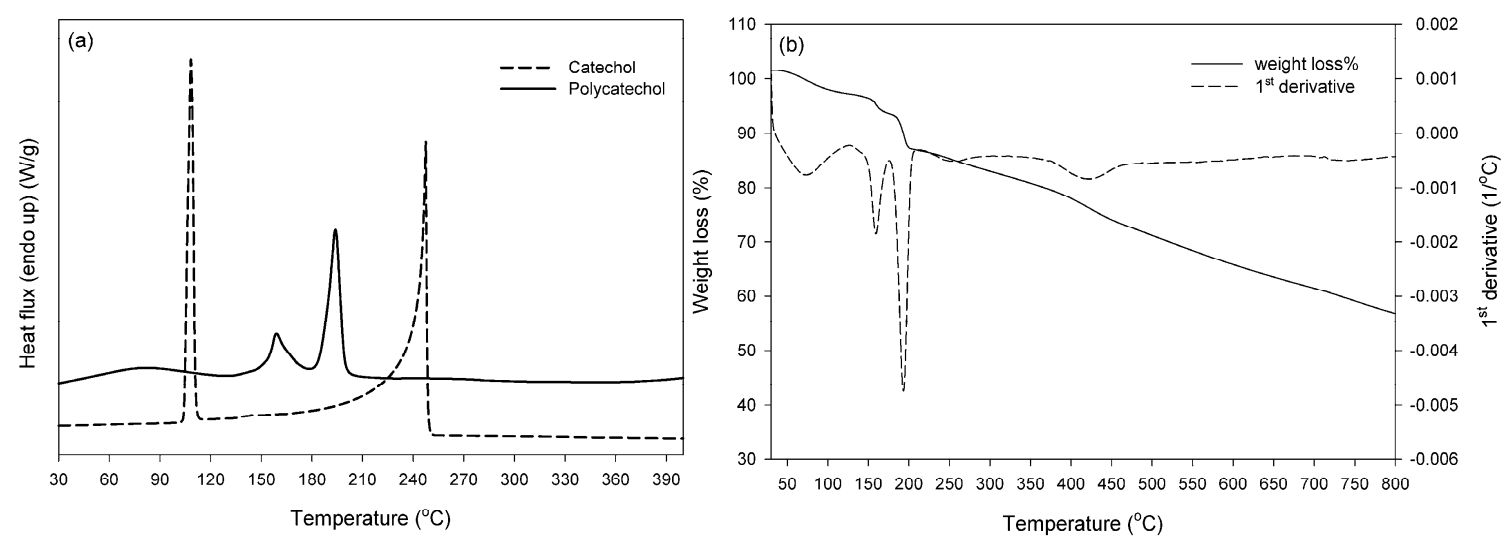

Figure 5. Thermal analysis curves (a) DSC and (b) TGA of enzymatically synthesized polycatechol.

\subsection{Molecular Weight Distributions from GPC and Viscosity Measurements}

In regard to molecular weight estimation, IV values measured in DMSO $\left(30^{\circ} \mathrm{C}\right)$ for polycatechol and poly(gallic acid) were $0.102 \pm 0.013 \mathrm{dL} \cdot \mathrm{g}^{-1}$ and $0.058 \pm 0.002 \mathrm{dL} \cdot \mathrm{g}^{-1}$, respectively. Polymerization rate appears to decrease as the repeating unit becomes more complex, with poly(gallic acid) presenting the lower yield and MW after $24 \mathrm{~h}$ of reaction. The viscosity results can be compared with the weight-average molecular weight $\left(\overline{\mathrm{M}_{\mathrm{W}}}\right)$ values measured in GPC analysis. When comparing $\overline{\mathrm{M}_{\mathrm{w}}}$ values it can be seen, that the higher IV value $\left(0.102 \mathrm{dL} \cdot \mathrm{g}^{-1}\right)$ of polycatechol corresponded to the higher $\overline{\mathrm{M}_{\mathrm{W}}}(26,240 \mathrm{Da})$ vs. the lower IV value $\left(0.058 \mathrm{dL} \cdot \mathrm{g}^{-1}\right)$ of poly(gallic acid) and the lower $\overline{\mathrm{M}_{\mathrm{w}}}(7600 \mathrm{Da})$. Furthermore, polycatechol samples presented a polydispersity index (PDI) of 15.4, a significantly higher PDI value than previously reported. Most of the previous efforts concerning the enzymatic polymerization of catechol resulted in products of $\overline{M_{n}}$ up to 2660 Da with narrow polymer distribution, reflected by PDI values up to $1.2[3,10,25]$, a discrepancy that can probably be attributed to the reaction conditions. Poly(gallic acid) samples, on the other hand, exhibited a $\overline{M_{n}}$ value of $2160 \mathrm{Da}$, with a PDI of 3.5, while it should be mentioned that this is the first report of a GPC analysis for enzymatically synthesized gallic acid polymers. Taking into account the molecular weight 
of the respective repeating units, the number-average degree of polymerization for the two polymers is calculated equal to 12.7 for poly(gallic acid) and 15.5 for polycatechol. The detailed results for all molecular weight determinations are presented in Table S1 in the Supplementary Materials.

\subsection{Thermal Properties}

The thermal properties of the synthesized products were investigated by differential scanning calorimetry and thermogravimetric analysis. Starting with the DSC results, analysis was also performed on the relevant monomers so as to monitor any residual amounts in the precipitated products. Catechol presented melting temperature at $106.2 \pm 0.7^{\circ} \mathrm{C}$ and boiling point at $244.6 \pm 0.1^{\circ} \mathrm{C}$ in agreement with literature values [27], while these peaks were not detected in the synthesized polymer. The formed polycatechol exhibited a broad endotherm in the range of $60-120^{\circ} \mathrm{C}$ attributed to moisture/water evaporation, as well as two distinct endotherms: a small peak at $158.6 \pm 0.3^{\circ} \mathrm{C}$ and a main one at $193.4 \pm 0{ }^{\circ} \mathrm{C}$ with total enthalpy $(\Delta H)$ at $239.1 \pm 1.9 \mathrm{~J} \cdot \mathrm{g}^{-1}$ (Figure 5a).

This double melting behavior can be a result of a bimodal distribution of crystal sizes, derived from different type or molecular-weight macromolecules, and/or from small or imperfect crystals [28-30]. DSC analysis of polycatechol has been also performed by Aktas et al. [25], who found a melting point at the lower temperature of $125^{\circ} \mathrm{C}$, probably due to the low number-average molecular weight $(813 \mathrm{Da})$ of the relevant product. The DSC data were herein combined with TGA analysis, so as to evaluate polymer thermal resistance. Depending on the enzymatic polymerization conditions, differences in polycatechol TGA thermal behavior can be found in the literature $[16,25,26]$. In all cases there is a slight weight loss $(<10 \%)$ up to $150^{\circ} \mathrm{C}$ attributed to water, and then decomposition starts: the number of stages, the rate and the thermal stability vary with monomer and enzyme type. Accordingly, the herein synthesized polycatechol presented a slight weight loss $(3 \%-4 \%)$ up to $140{ }^{\circ} \mathrm{C}$, due to moisture and absorbed water (Figure 5b). Then, three stages of weight loss were observed, with maximum values at $157.6,190.9$ and $424.4^{\circ} \mathrm{C}$. The first two stages coincide with DSC endotherms, implying gravimetric effects (up to $13 \%$ weight loss) on melting: this can be attributed (i) to further loss of trapped solvent (water) immediately followed polymer melting; (ii) increasing vapour pressure of the volatile melt and/or (iii) partial decomposition of the polymer in the melt phase [31]. For temperatures above $200{ }^{\circ} \mathrm{C}$, it is interesting to note that the degradation rate was relatively low compared to conventional polymeric materials, and the residue was found 57\% up to $800{ }^{\circ} \mathrm{C}$, slightly higher than the findings (65\% mass loss) for laccase-synthesized polycatechol in the work of Aktas et al. [25]. It is important to note that in the aforementioned study the authors used a high redox potential laccase from T. versicolor. On the other hand, enzymatic synthesis with horseradish peroxidase [26], soybean peroxidase [26] and porphyrin [16] resulted in residues lower than $40 \%$, implying the higher stability of the herein synthesized polycatechol. Similarily, in the case of purpurogallin (Figure $6 \mathrm{a})$, the melting $\left(131.7 \pm 2.5^{\circ} \mathrm{C}\right)$ and boiling $\left(303.3 \pm 0.4{ }^{\circ} \mathrm{C}\right)$ endotherms of the monomer (consistent with those reported by the supplier-Safety Data Sheet, product code 100612, Merck Millipore, Darmstadt, Germany) were not detected in the DSC curve of the synthesized product. Purpurogallin presented a melting endotherm at a higher temperature than polycatechol, i.e., at $c a .280 .15 \pm 0.1^{\circ} \mathrm{C}\left(\Delta H_{\text {total }}=103.2 \pm 0.9 \mathrm{~J} \cdot \mathrm{g}^{-1}\right)$. Regarding the TGA curve (Figure $\left.6 \mathrm{~b}\right)$, a slight weight loss was also found up to $140{ }^{\circ} \mathrm{C}$ due to moisture and absorbed water. Then, two stages of weight loss were seen, the first at $295.2{ }^{\circ} \mathrm{C}$, i.e., at higher temperature compared to polycatechol, and the second at $402{ }^{\circ} \mathrm{C}$ associated to degradation which resulted in total in residue less than $40 \%$ for temperature up to $800^{\circ} \mathrm{C}$. However, it should be noted that the weight loss upon purpurogallin melting $\left(295^{\circ} \mathrm{C}\right)$ was considerably higher $(30 \%)$ than polycatechol $(13 \%)$, indicating that gravimetric effects on melting can be mainly correlated to simultaneous dimer degradation obviously due to the higher melting temperature. Such thermal characteristic complicates the application of conventional melt polymerization techniques, and enhances the need for the development of alternative polymerization processes under mild conditions, as the enzymatic approach, which is applied in the current paper. 

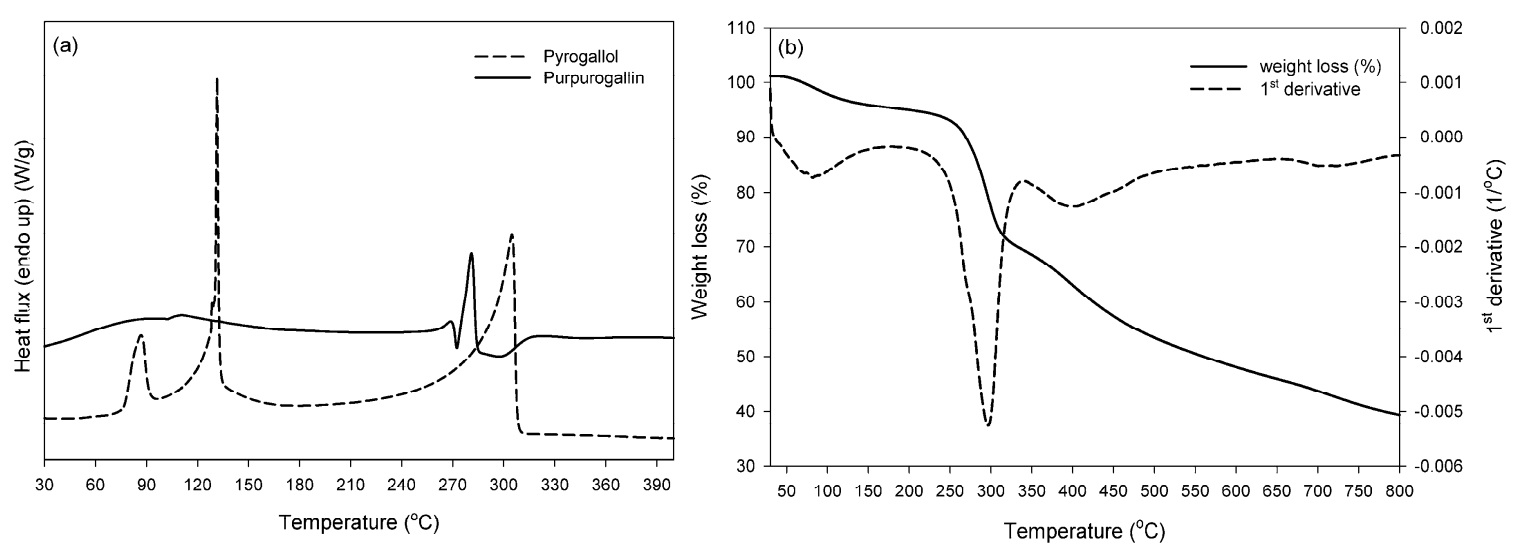

Figure 6. Thermal analysis curves (a) DSC and (b) TGA of enzymatically synthesized purpurogallin.

Finally, regarding poly(gallic acid) thermal behavior, monomer at $266^{\circ} \mathrm{C}$ was not detected in the polymer samples (Figure 7a), while a broad endotherm was again shown in the area of $100^{\circ} \mathrm{C}$ due to water/moisture evaporation. Small melting peaks appeared at 147 and $165^{\circ} \mathrm{C}$ with no significant gravimetric effects in the TGA (Figure 7b). No sharp melting endotherm was evidenced as in the case of polycatechol, obviously due to its amorphous character in agreement also with the lowest molecular weight that it possessed. The degradation rate presented a maxiumum value at $331{ }^{\circ} \mathrm{C}$ resulting in $25 \%$ up to $800^{\circ} \mathrm{C}$. Again, however, it should be noted that slow degradation was observed, a result that confirms the relatively high thermal resistance of the enzymatically synthesized polymers. Especially in the case of gallic acid polymer, the remaining residue above $200{ }^{\circ} \mathrm{C}$ is over $80 \%$, equally satisfactory with previously reported polymerization efforts with T. versicolor laccase [26].
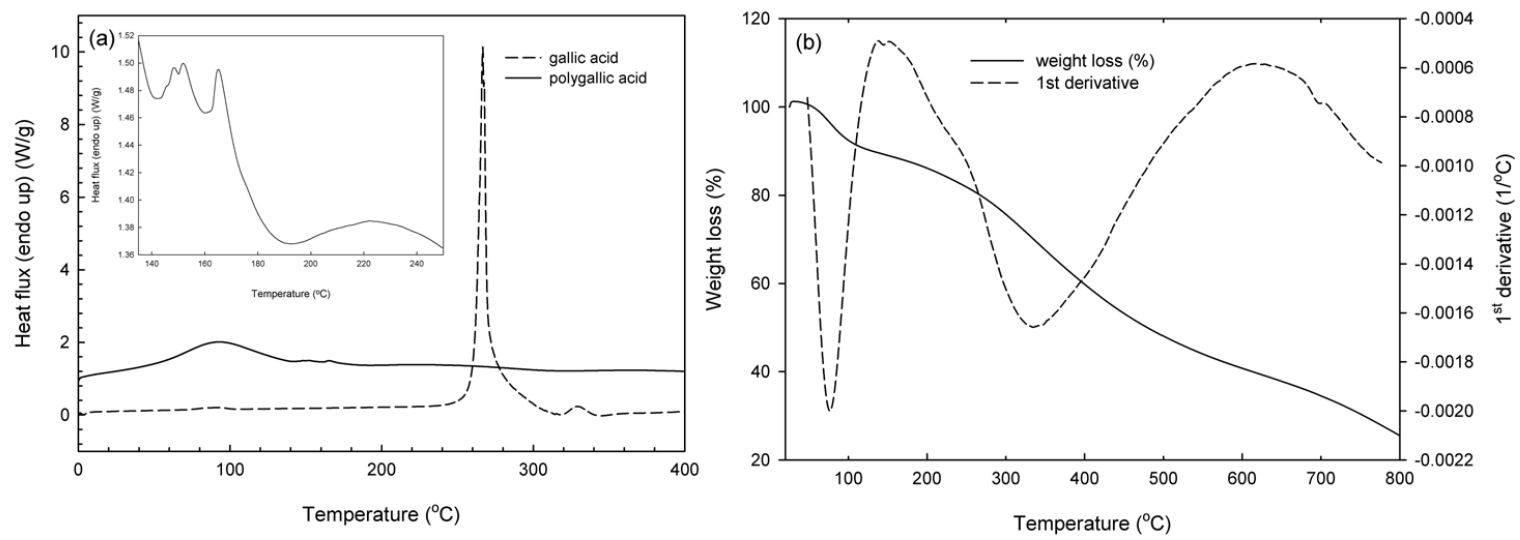

Figure 7. Thermal analysis curves (a) DSC and (b) TGA of enzymatically synthesized poly(gallic acid).

\section{Materials and Methods}

\subsection{Enzymes and Chemicals}

All chemicals were purchased from either Applichem (Darmstadt, Germany) or Sigma-Aldrich (Taufkirchen, Germany) and were of the highest purity available. Pyrogallol was purchased from Merck Millipore (Darmstadt, Germany). For the polymerization reactions, a commercial laccase (multicopper oxidase EC 1.10.3.2) from M. thermophila, expressed in Aspergillus oryzae, named Novozym 51003, was kindly provided by Novo Nordisk A/S (Bagsvaerdt, Denmark). The commercial enzyme preparation was provided in liquid form, and according to the manufacturer, its activity was 1000 LAMU g $^{-1}$. 


\subsection{Determination of Laccase Activity and Protein Concentration}

Laccase activity was routinely estimated using 2,2'-azino-bis(3-ethylbenzothiazoline-6-sulphonic acid (ABTS) as the substrate. The reaction mixture contained $3 \mathrm{mM}$ ABTS, a properly diluted enzyme sample and $100 \mathrm{mM}$ phosphate buffer $\mathrm{pH}$. After a $10 \mathrm{~min}$ incubation at $30{ }^{\circ} \mathrm{C}$, the absorbance was measured at $420 \mathrm{~nm}$, and the concentration of oxidized ABTS was calculated using $\varepsilon_{420 \mathrm{~nm}}=36000 \mathrm{M}^{-1} \cdot \mathrm{cm}^{-1}$. Control reactions were also performed with thermally inactivated enzyme. One unit of laccase activity was defined as the amount of enzyme required to oxidize $1 \mu \mathrm{mol}$ of ABTS per minute in the above conditions. The activity of the laccase preparation was found to be $134.58 \pm 8.8 \mathrm{U} \cdot \mathrm{mL}^{-1}$. Protein concentration was estimated using the Lowry method [32], using bovine serum albumin as the standard. The commercial preparation was found to contain $51.57 \pm 2.31 \mathrm{mg} \cdot \mathrm{mL}^{-1}$ protein.

\subsection{Bioconversion Reactions}

A typical polymerization/dimerization reaction was carried out as follows: in $250 \mathrm{~mL}$ Erlenmeyer flasks 89 Units $\mathrm{mL}^{-1}$ of commercial laccase and $400 \mathrm{mg}$ substrate were added in $100 \mathrm{~mL}$ of sodium phosphate buffer $50 \mathrm{mM}, \mathrm{pH}$ 6. The reaction mixture was incubated for $24 \mathrm{~h}$ in a temperature-controlled shaking incubator, at $30^{\circ} \mathrm{C}, 180 \mathrm{rpm}$, unless stated otherwise. The studied substrates were catechol, pyrogallol and gallic acid. Control reactions were carried out with heat inactivated enzyme, to eliminate any possible background oxidation of substrates. After $24 \mathrm{~h}$, the mixture was filtered with a $0.2 \mu \mathrm{m}$ hydrophilic polyethersulfone filter and the solids retained were washed with ultrapure water to remove enzyme and unreacted monomers. The reaction product was freeze-dried prior to analysis. For the optimization of the polymerization reaction conditions on different values of $\mathrm{pH}$ and temperature, reactions were carried out in smaller volumes $(25 \mathrm{~mL})$ using catechol or pyrogallol as the substrate. The optimum $\mathrm{pH}$ of polymerization reactions was investigated using the following buffers: 100 mM sodium phosphate-citrate buffer ( $\mathrm{pH}$ 3-5), $100 \mathrm{mM}$ sodium phosphate buffer ( $\mathrm{pH}$ 6-7).

\subsection{Product Analysis}

UV-Vis spectra were recorded with a U-2900 UV-Visible spectrophotometer (Hitachi, Tokyo, Japan) in the range of 200-700 nm. FT-IR spectra were recorded with a Nicolet Magna-IR 560 Spectrophotometer (Thermo Fisher Scientific Inc., Waltham, MA, USA) in the 4000-400 cm $\mathrm{range}^{-1}$ in the form of $\mathrm{KBr}$ pellets. ${ }^{1} \mathrm{H}-\mathrm{NMR}$ analyses were recorded on an Avance III 600 spectrometer (Bruker, Billerica, MA, USA) with DMSO- $d_{6}$ as solvent and TMS as an internal standard. DSC analysis was performed using a DSC 1 STARe System (Mettler, Greifensee, Switzerland) under nitrogen flow $\left(10 \mathrm{~mL} \cdot \mathrm{min}^{-1}\right)$. Approximately 5-6 $\mathrm{mg}$ of sample were subjected to heating from $0{ }^{\circ} \mathrm{C}$ to $400{ }^{\circ} \mathrm{C}$ at a rate of $10^{\circ} \mathrm{C} \cdot \mathrm{min}^{-1}$ in duplicate runs. TGA was also conducted on a Mettler TGA/DSC1 thermobalance with a heating rate at $10^{\circ} \mathrm{C} \cdot \mathrm{min}^{-1}$ from 30 to $800^{\circ} \mathrm{C}$ under nitrogen flow $\left(20 \mathrm{~mL} \cdot \mathrm{min}^{-1}\right)$. Degradation temperatures $\left(T_{\mathrm{d}}\right)$ were determined at the maximum weight loss. The intrinsic viscosity $\left(\mathrm{IV}, \mathrm{dL} \cdot \mathrm{g}^{-1}\right)$ was measured in DMSO at concentration of $0.2 \mathrm{~g} \cdot \mathrm{dL}^{-1}$ in an Ubbelohde capillary viscometer at $30 \pm 0.1^{\circ} \mathrm{C}$. All samples were dissolved at room temperature and filtered prior measurement using filter paper. Measurements were performed in duplicates and IV values were determined using the Solomon-Ciuta equation (Equation (1)) [33]:

$$
I V=\sqrt{2\left(\frac{t}{t_{0}}-\ln \frac{t}{t_{0}}-1\right)}
$$

where, $t$ is the flow time of solution and $t_{0}$ is the flow time of pure solvent.

Gel Permeation Chromatography was carried out using a Shimadzu Analytical HPLC (Kyoto, Japan) equipped with a RID-10A-SPD M20A refractive index detector, and a PL Gel packed column (Agilent, Santa Clara, CA, USA). Samples were dissolved in tetrahydrofuran, and the injection amount of the sample was $5 \mu \mathrm{g}$. The flow rate was maintained at $0.75 \mathrm{~mL} \cdot \mathrm{min}^{-1}$ with a column temperature of 
$40{ }^{\circ} \mathrm{C}$. A calibration curve of polystyrene with molecular weight ranged from 162 to 5,000,000 Da was used for the calculations of the average molecular weight and polydispersity.

\section{Conclusions}

The use of oxidative enzymes, such as laccases and peroxidases for synthetic applications is emerging as an attractive alternative to conventional chemical synthesis methods. On the other hand, such biocatalytic tools permit the biosynthesis of novel materials with relatively low financial and environmental costs. Especially for oxidative enzymes, their major advantage could be that they offer a means to exploit simple phenols as building blocks, a resource abundantly available through lignin-rich byproducts of various processes, such as the paper and pulp industry. In the present paper, we examined the potential of a thermostable commercial laccase for the polymerization and dimerization of biomass derived phenols and their characterization. Our results further support the prominence of enzymes as tools for polymer synthesis, due to the observation that the structure and physical properties of the desired material can be, at least to a certain extent, controlled by the choice of the monomer unit and/or the biocatalyst. Further work is needed in order to explore whether the final product and its physicochemical properties depends also on other factors, such as the choice of the solvent, the enzyme/substrate ratio, the duration of the reaction etc. Research in this direction could possibly lead to the production of custom-made materials and bioactive compounds with distinct properties for specific applications.

Supplementary Materials: The following are available online at: http:/ /www.mdpi.com/1420-3049/21/5/550/s1, Figure S1: ${ }^{1} \mathrm{H}-\mathrm{NMR}$ spectrum of polycatechol, Figure S2: ${ }^{1} \mathrm{H}-\mathrm{NMR}$ spectrum of purpurogallin, Table S1: GPC results and solution viscosity measurements for laccase-synthesized polycatechol and poly(gallic acid).

Acknowledgments: A.Z. thanks Research Funding Program THALIS-UOA-MIS 377062, co-financed by the European Union (European Social Fund-ESF) and Greek national funds through the Operational Program "Education and Lifelong Learning" of the National Strategic Reference Framework (NSRF). Commercial laccase from M. thermophila was kindly provided by Novo Nordisk A/S. E.T and P.C would like to thank Bio4Energy, a Strategic Research Environment appointed by the Swedish Government for supporting the work. Authors would also like to thank Claudia Crestini, Heiko Lange and Anthi Karnaouri from University of Rome Tor Vergata, Dipartimento di Scienze e Tecnologie Chimiche for the GPC analysis of polycatechol and poly-gallic acid.

Author Contributions: E.T. conceived and designed the experiments; A.Z. and N.M. performed the experiments; A.Z. and S.V. analyzed the data; P.C. contributed reagents/materials/analysis tools; E.T. and A.Z. wrote the paper.

Conflicts of Interest: The authors declare no conflict of interest.

\section{References}

1. Ward, G.; Parales, R.E.; Dosoretz, C.G. Biocatalytic synthesis of polycatechols from toxic aromatic compounds. Environ. Sci. Technol. 2004, 38, 4753-4757. [CrossRef] [PubMed]

2. Aktas, N.; Tanyolac, A. Kinetics of laccase-catalyzed oxidative polymerization of catechol. J. Mol. Catal. B Enzym. 2003, 22, 61-69. [CrossRef]

3. Sun, X.; Bai, R.; Zhang, Y.; Wang, Q.; Fan, X.; Yuan, J.; Cui, L.; Wang, P. Laccase-catalyzed oxidative polymerization of phenolic compounds. Appl. Biochem. Biotechnol. 2013, 171, 1673-1680. [CrossRef] [PubMed]

4. Reihmann, M.; Ritter, H. Synthesis of phenol polymers using peroxidases. In Enzyme-Catalyzed Synthesis of Polymers; Kobayashi, S., Ritter, H., Kaplan, D., Eds.; Springer: Berlin, Heidelberg, Germany, 2006; Volume 194, pp. 1-49.

5. Zerva, A.; Christakopoulos, P.; Topakas, E. Characterization and application of a novel class II thermophilic peroxidase from Myceliophthora thermophila in biosynthesis of polycatechol. Enzym. Microb. Technol. 2015, 75-76, 49-56. [CrossRef] [PubMed]

6. Desentis-Mendoza, R.M.; Hernández-Sánchez, H.; Moreno, A.; Rojas del C., E.; Chel-Guerrero, L.; Tamariz, J.; Jaramillo-Flores, M.E. Enzymatic polymerization of phenolic compounds using laccase and tyrosinase from Ustilago maydis. Biomacromolecules 2006, 7, 1845-1854. [CrossRef] [PubMed] 
7. Khlupova, M.E.; Vasileva, I.S.; Shumakovich, G.P.; Morozova, O.V.; Chertkov, V.A.; Shestakov, A.K.; Kisin, A.V.; Yaropolov, A.I. Enzymatic polymerization of dihydroquercetin using bilirubin oxidase. Biochemistry 2015, 80, 233-241. [CrossRef] [PubMed]

8. Aktas, N.; Tanyolac, A. Reaction conditions for laccase catalyzed polymerization of catechol. Bioresour. Technol. 2003, 87, 209-214. [CrossRef]

9. Mustafa, R.; Muniglia, L.; Rovel, B.; Girardin, M. Phenolic colorants obtained by enzymatic synthesis using a fungal laccase in a hydro-organic biphasic system. Food Res. Int. 2005, 38, 995-1000. [CrossRef]

10. Kim, S.; Silva, C.; Evtuguin, D.; Gamelas, J.F.; Cavaco-Paulo, A. Polyoxometalate/laccase-mediated oxidative polymerization of catechol for textile dyeing. Appl. Microbiol. Biotechnol. 2011, 89, 981-987. [CrossRef] [PubMed]

11. Jeon, J.R.; Kim, E.J.; Murugesan, K.; Park, H.K.; Kim, Y.M.; Kwon, J.H.; Kim, W.G.; Lee, J.Y.; Chang, Y.S. Laccase-catalysed polymeric dye synthesis from plant-derived phenols for potential application in hair dyeing: Enzymatic colourations driven by homo- or hetero-polymer synthesis. Microb. Biotechnol. 2010, 3, 324-335. [CrossRef] [PubMed]

12. Fu, J.; Nyanhongo, G.S.; Gübitz, G.M.; Cavaco-Paulo, A.; Kim, S. Enzymatic colouration with laccase and peroxidases: Recent progress. Biocatal. Biotransform. 2012, 30, 125-140. [CrossRef]

13. Polak, J.; Jarosz-Wilkolazka, A. Fungal laccases as green catalysts for dye synthesis. Process Biochem. 2012, 47, 1295-1307. [CrossRef]

14. Kurisawa, M.; Chung, J.E.; Uyama, H.; Kobayashi, S. Laccase-catalyzed synthesis and antioxidant property of poly(catechin). Macromol. Biosci. 2003, 3, 758-764. [CrossRef]

15. Wang, P.; Martin, B.D.; Parida, S.; Rethwisch, D.G.; Dordick, J.S. Multienzymic synthesis of poly(hydroquinone) for use as a redox polymer. J. Am. Chem. Soc. 1995, 117, 12885-12886. [CrossRef]

16. Nabid, M.; Zamiraei, Z.; Sedghi, R.; Nazari, S. Synthesis and characterization of poly(catechol) catalyzed by porphyrin and enzyme. Polym. Bull. 2010, 64, 855-865. [CrossRef]

17. He, J.; Guan, Y.; Zhang, Y. Redox-active LBL films via in situ template polymerization of hydroquinone. J. Appl. Polym. Sci. 2013, 129, 3070-3076. [CrossRef]

18. Marczewska, B.; Przegalinski, M. Poly(catechol) electroactive film and its electrochemical properties. Synth. Met. 2013, 182, 33-39. [CrossRef]

19. Tanaka, T.; Takahashi, M.; Hagino, H.; Nudejima, S.I.; Usui, H.; Fujii, T.; Taniguchi, M. Enzymatic oxidative polymerization of methoxyphenols. Chem. Eng. Sci. 2010, 65, 569-573. [CrossRef]

20. Miyazaki, K.; Arai, S.; Iwamoto, T.; Takasaki, M.; Tomoda, A. Metabolism of pyrogallol to purpurogallin by human erythrocytic hemoglobin. Tohoku. J. Exp. Med. 2004, 203, 319-330. [CrossRef] [PubMed]

21. Ku, S.K.; Bae, J.S. Antiplatelet and antithrombotic activities of purpurogallin in vitro and in vivo. BMB Rep. 2014, 47, 376-381. [CrossRef] [PubMed]

22. Sugiyama, H.; Fung, K.P.; Wu, T.W. Purpurogallin as an antioxidant protector of human erythrocytes against lysis by peroxyl radicals. Life Sci. 1993, 53, 139-143. [CrossRef]

23. López, J.; Hernández-Alcántara, J.M.; Roquero, P.; Montiel, C.; Shirai, K.; Gimeno, M.; Bárzana, E. Trametes versicolor laccase oxidation of gallic acid toward a polyconjugated semiconducting material. J. Mol. Catal. B Enzym. 2013, 97, 100-105. [CrossRef]

24. Rouet-Mayer, M.A.; Ralambosoa, J.; Philippon, P. Roles of o-quinones and their polymers in the enzymic browning of apples. Phytochemistry 1990, 29, 435-440. [CrossRef]

25. Aktas, N.; Sahiner, N.; Kantoglu, O.; Salih, B.; Tanyolac, A. Biosynthesis and characterization of laccase catalyzed poly(catechol). J. Polym. Environ. 2003, 11, 123-128. [CrossRef]

26. Dubey, S.; Singh, D.; Misra, R. A. Enzymatic synthesis and various properties of poly(catechol). Enzym. Microb. Technol. 1998, 23, 432-437. [CrossRef]

27. Fiege, H.; Voges, H.W.; Hamamoto, T.; Umemura, S.; Iwata, T.; Miki, H.; Fujita, Y.; Buysch, H.J.; Garbe, D.; Paulus, W. Phenol derivatives. In Ullmann's Encyclopedia of Industrial Chemistry; Wiley-VCH Verlag GmbH \& Co. KGaA: Weinheim, Germany, 2000. [CrossRef]

28. Jamshidi, K.; Hyon, S.; Ikada, Y. Thermal characterization of polylactides. Polymer 1988, 29, $2229-2234$. [CrossRef]

29. Vouyiouka, S.; Filgueiras, V.; Papaspyrides, C.; Pinto, J.; Lima, E. Morphological changes of poly(ethylene terephthalate-co-isophthalate) during solid state polymerization. J. Appl. Polym. Sci. 2012, 124, 4457-4465. [CrossRef] 
30. Vouyiouka, S.; Theodoulou, P.; Symeonidou, A.; Papaspyrides, C.D.; Pfaendner, R. Solid state polymerization of poly(lactic acid): Some fundamental parameters. Polym. Degrad. Stab. 2013, 98, 2473-2481. [CrossRef]

31. Gabbott, P. Principles and Applications of Thermal Analysis; Blackwell: Oxford, UK, 2008; p. 101.

32. Lowry, O.H.; Rosebrough, N.J.; Farr, A.L.; Randall, R.J. Protein measurement with the Folin phenol reagent. J. Biol. Chem. 1951, 193, 265-275. [PubMed]

33. Solomon, O.F.; Ciuta, I.Z. Détermination de la viscosité intrinsèque de solutions de polymères par une simple détermination de la viscosité. J. Appl. Polym. Sci. 1962, 6, 683. [CrossRef]

Sample Availability: Not Available.

(C) 2016 by the authors; licensee MDPI, Basel, Switzerland. This article is an open access article distributed under the terms and conditions of the Creative Commons Attribution (CC-BY) license (http://creativecommons.org/licenses/by/4.0/). 